\title{
(C) OPEN ACCESS \\ Feasibility and acceptability of a patient-reported outcome intervention in chronic heart failure
}

\author{
Pauline M Kane, ${ }^{1}$ Barbara A Daveson, ${ }^{1}$ Karen Ryan, ${ }^{2}$ Clare I Ellis-Smith, ${ }^{1}$ \\ Niall G Mahon, ${ }^{3}$ Brendan McAdam, ${ }^{4}$ Regina McQuillan, Cecelia Tracey, ${ }^{3}$ \\ Christine Howley, ${ }^{3}$ Geraldine O'Gara, ${ }^{4}$ Caroline Raleigh, ${ }^{4}$ \\ Irene J Higginson, ${ }^{1}$ Jonathan Koffman, ${ }^{1}$ Fliss E M Murtagh, ${ }^{1,5}$ on behalf \\ of BuildCARE
}

- Additional material is published online only. To view please visit the journal online (http://dx.doi.org/10.1136/ bmjspcare-2017-001355)

${ }^{1}$ Department of Palliative Care, Policy and Rehabilitation, King's College London, Cicely Saunders Institute, London, UK

${ }^{2}$ Palliative Care, St. Francis Hospice and Mater Misericordiae University Hospital, Dublin, Ireland

${ }^{3}$ Cardiology, Mater Misericordiae University Hospital, Dublin 7, Ireland

${ }^{4}$ Cardiology, Beaumont Hospital, Dublin, Ireland

${ }^{5}$ Wolfson Palliative Care Research Centre, Hull York Medical School, Hull, UK

\section{Correspondence to} Dr Pauline M Kane, Department of Palliative Care, Policy and Rehabilitation, King's College London, Cicely Saunders Institute, Bessemer Road, London SE5 9PJ, UK;

pauline.m.kane@kcl.ac.uk

Received 29 March 2017

Revised 6 July 2017

Accepted 26 July 2017

Published Online First

1 September 2017

\section{(-)...}

To cite: Kane PM, Daveson BA, Ryan K, et al. BMJ Supportive \& Palliative Care 2017;7:470-479.

\section{ABSTRACT}

Patients with chronic heart failure (CHF) have symptoms and concerns which are inadequately addressed. Patient-reported outcome measures (PROMs) can potentially improve the identification and management of advanced symptoms and palliative concerns. However, these have not been used in CHF.

Objectives To examine the feasibility and acceptability of using a PROM - the Integrated Palliative care Outcome Scale (IPOS) — together with heart failure nurse education and training to improve the identification and management of symptoms and concerns among patients with CHF.

Methods A parallel, mixed methods design with an embedded qualitative component was used to examine the feasibility of recruitment, retention, intervention adherence/compliance and follow-up assessment completion (symptom burden, quality of life, psychological well-being). Patient and nurse qualitative semistructured interviews explored intervention and study design feasibility and its acceptability.

Results Conversion to consent was $46.9 \%$ (372 screened, 81 approached, 38 recruited). $66 \%$ of patient participants completed the IPOS; $6 \%$ of IPOS questionnaire items were missing (non-response). Over two-thirds (65.6\%) of these missing items related to three patients. No item was consistently missing; appetite was the most frequent missing item (1.4\%). 92\% of participants who completed the IPOS completed all follow-up assessments (1-2 days, 1-2 weeks and 4-6 weeks post-IPOS completion) with no missing data. The a priori feasibility objectives were met. Patients and nurses reported the intervention and study design feasible and acceptable.

Conclusions A palliative-specific PROM-based intervention is feasible and acceptable to both patients with $\mathrm{CHF}$ and nurses in nurse-led disease management clinics for the purposes of both clinical care and research.

\section{INTRODUCTION}

Chronic heart failure (CHF) affects $1 \%-2 \%$ of the adult population and is characterised by high symptom burden and volatility with up to a $50 \%$ sudden death risk. ${ }^{1}$ The Innovative Care for Chronic Conditions (ICCC) framework recommends, for chronic conditions including $\mathrm{CHF}$, that patients become active, prepared and informed rather than passive healthcare recipients. ${ }^{2}$ Policy makers advise a patient-centred approach for CHF involving a holistic patients' needs assessment and care goal preference identification ${ }^{3-5}$; aspects of care sharing a similar philosophy with palliative care. ${ }^{6}$ Patient-centred care can act to facilitate the integration of a palliative care approach into CHF management for patients with deteriorating health and high mortality risk. ${ }^{6}$

Patient-centred CHF interventions reduce symptom burden and increase patient engagement, by enabling patients to identify their needs, communicate these needs and collaborate with healthcare professionals to address these needs according to patients' preferences. ${ }^{6}$ This process is difficult to evaluate. ${ }^{7}$ Tools to help patients with $\mathrm{CHF}$ to do this are lacking.

Patient-reported outcome measures (PROMs) facilitate patient-centred care ${ }^{8}$ by providing a subjective assessment of patients' perceptions of their own health status. ' PROMs identify patients' unmet needs by helping patients communicate their problems to healthcare 
professionals. ${ }^{8}$ Given the paucity of CHF palliative care needs assessment research, palliative-specific PROM use to identify patients' advanced symptoms and palliative concerns is timely. This intervention involves the Integrated Palliative care Outcome Scale (IPOS), a PROM designed to capture palliative symptoms and concerns, ${ }^{10}$ with integrated healthcare professional education and training. The intervention's aim is to improve identification and management of CHF advanced symptoms and palliative concerns.

\section{METHODS}

\section{Design}

As recommended by the Medical Research Council's (MRC) framework for the development and evaluation of complex interventions, ${ }^{11}$ a feasibility and acceptability study was undertaken to test the following methodological components: recruitment, retention, intervention compliance/adherence, intervention acceptability, follow-up assessment completion and possible effect size to inform selected follow-up measures appropriateness. This study used a parallel, mixed methods embedded research design, ${ }^{12}$ comprising a pre-post uncontrolled quantitative component and embedded qualitative component. This design was chosen to inform the feasibility and acceptability objectives for a future pilot cluster randomised controlled trial (RCT).

\section{Setting and sample}

Patients attending nurse-led CHF disease management clinics in two national tertiary referral centres in Dublin, Ireland were eligible if they had CHF; New York Heart Association (NYHA) functional class III-IV, with systolic dysfunction and left ventricular ejection fraction (HFrEF) of $<40 \%$ or heart failure symptoms and either midrange systolic function (HFmrEF): 40\%-49\% or preserved systolic function $(\mathrm{HFpEF}) \geq 50 \%$; fluency and literacy in English; sufficient cognitive function to complete the questionnaires and were $\geq 18$ years of age. Cognitive function was assessed clinically by the nurses. Patient inclusion criteria were developed in conjunction with the heart failure nurses involved in intervention delivery, were based on the 2012 European Society of Cardiology's CHF definition ${ }^{13}$ and included HFpEF. ${ }^{1}$ The 2016 European Society of Cardiology's CHF definition ${ }^{14}$ does now include HFpEF in its definition. Recruited patients' caregivers were eligible if they were $\geq 18$ years of age, provided unpaid care, and had capacity to complete the questionnaires. The caregivers were identified by the patient.

\section{Recruitment}

Nurses involved in the nurse-led clinics were invited to participate in the patient recruitment, the intervention and qualitative semistructured interviews postintervention. They identified and approached eligible clinic patients with study information and obtained permission for the researcher to contact them, who then consented interested patients. Where patients with an identified caregiver agreed, caregivers were approached and consented.

\section{Ethics}

Ethics approval was obtained from Research Ethics Committees at hospital sites (Ref: 13/70 and Ref: 1/378/1579) and King's College London (Ref: $\mathrm{BDM} / 13 / 14-25)$. Written informed consent was obtained from patients, caregivers and participating nurses. A Project Advisory Group comprising expert clinicians, researchers and a service user was established to discuss study findings and to inform the evaluation.

\section{Sample size}

While a sample size was not calculated (outcomes of interest were intervention and study design feasibility and acceptability), a minimum of 20 patients was required; the number considered adequate to identify $95 \%$ of IPOS usability problems. ${ }^{1516}$ This intervention was delivered at a service level rather than at a patient level. In a full-scale study, service level randomisation as part of a cluster trial would be appropriate. For this study, involving only two sites, service level randomisation was therefore not possible, so the feasibility of randomisation was not tested.

\section{Intervention}

The IPOS (see online supplementary appendix 1) with integrated heart failure nurse education and training was delivered alongside best standard care (box). (Intervention description follows template for intervention description and replication guidelines.) ${ }^{17}$ Once nurses at each site had received patient-centred care education and IPOS training, they gave recruited patients the IPOS to complete at the subsequent clinic visit. The IPOS has 10 questions with two open questions covering patients' main concerns and symptoms, respectively, and a five-point Likert scale (0-4) accompanying common symptoms, patient and family distress, existential well-being, sharing feelings with family, information available and practical concerns. ${ }^{10}$

\section{Baseline and follow-up measures}

The intervention aimed to reduce symptom burden and improve quality of life $^{6}$; this informed follow-up measure selection. The feasibility and acceptability of the selected study measures were assessed to determine those most appropriate for a definitive trial. The primary follow-up measure was symptom burden, measured using the Edmonton Symptom Assessment System-revised (ESAS-r) which has been used successfully in CHF. ${ }^{21}$ Each of its nine symptoms is ranked on a scale of 0-10: 0 (absent symptom) and 10 (worst possible severity) with a 


\section{Box Description of the intervention}

\section{Integrated Palliative care Outcome Scale (IPOS) with integrated heart failure nurse (HFN) education and training Aims and rationale}

The intervention aimed to provide a subjective assessment of patients' palliative symptoms and concerns to improve their identification and management within the heart failure nursing clinical review. HFN education on patient-centred care and IPOS training aimed to facilitate optimal IPOS use. ${ }^{8}$ Following Knowles andragogy principles, ${ }^{18}$ HFNs were involved in the education and training development. Case studies using IPOS underwent external expert review to ensure clinical accuracy for patients with chronic heart failure (CHF). The IPOS has been designed to capture patients' palliative symptoms and concerns, which are well documented in CHF. ${ }^{19}$ The IPOS parent patient-reported outcome measure (PROM), the Palliative Care Outcome Scale has been used in $\mathrm{CHF}^{20}$ This intervention was developed using the Medical Research Council guidance and informed through a systematic review ${ }^{6}$ using the best available evidence ${ }^{4}$ and appropriate theory. ${ }^{8}$

\section{Content}

The intervention involved two components; Part one was HFN education on patient-centred care and IPOS training; Part two was the subsequent use of the IPOS with recruited patients in the clinic. The education and training followed a heterogeneous pedagogical approach with five components: (1) patient-centred care overview, (2) rationale for PROM use, (3) rationale for IPOS, (4) IPOS case studies and (5) practicalities of IPOS use in the clinic. The IPOS has 10 questions with two open questions covering patients' main concerns and symptoms, respectively, and a five-point Likert scale (0-4) accompanying common symptoms, patient and family distress, existential well-being, sharing feelings with family, information available and practical concerns. ${ }^{10}$ After delivery of the education and training to the HFNs, recruited patients completed the IPOS at their next clinic visit. HFNs then reviewed each patient with the completed IPOS. HFNs were advised to address individual items with scores $\geq 3$; use their clinical discretion for individual scores $\leq 2$; and assess any problems included in the open questions. No clinical guidelines were provided as HFNs were expected to use their clinical expertise in assessment and management of these symptoms/concerns, referring to other specialist services as they deemed appropriate. As the IPOS was used once with each patient, an overall IPOS score was not used.

\section{Personnel}

Provider: The primary researcher delivered the 1-hour patient-centred care education and IPOS training at each study site once to the HFNs. The HFNs provided recruited patients with the IPOS.

Supervision: The primary researcher was on site when recruited patients attended the nurse-led CHF disease management clinic, prompted the HFNs to give patients the IPOS and to remind patients to complete both sides and reminded HFNs to store completed IPOS in the provided repository.

\section{Format}

Setting: Patients completed the IPOS while waiting to be reviewed at the nurse-led CHF disease management clinic.

Schedule and duration: Twenty-five patients completed the IPOS. On arrival to the clinic, HFNs provided patients with a paper copy of the IPOS on a clipboard with a pen.

\section{Delivery}

Delivery methods: The HFNs were advised where patients requested assistance to complete the IPOS not to paraphrase, not to give their own explanations of the questions, to adhere to the questionnaire text and not to prompt patients with potential answers. Only HFNs who had attended the module subsequently were involved in IPOS patient delivery and clinical use.

global score range of 0-90. Secondary follow-up measures included: the Kansas City Cardiomyopathy Questionnaire (KCCQ), ${ }^{22}$ the Patient Health Questionnaire-8 (PHQ-8) ${ }^{23}$ and a quality of life visual analogue scale. The KCCQ is a 23 -item questionnaire quantifying functional limitations, symptoms, social limitations and quality of life in the preceding 2 weeks and is sensitive to patients with CHF health status changes. ${ }^{22}$ Scores range from 0 to 100; higher scores indicate a better health status. An intraindividual change of $\geq 5$ points is considered clinically significant. ${ }^{24}$ The PHQ-8 is an eight-item questionnaire with good psychometric properties in the CHF population. ${ }^{23}$ Scores range from 0 to 24 ; a score of $\geq 10$ indicates clinically significant depression requiring clinical review. ${ }^{25}$ Patients' perceived quality of life was assessed using a visual analogue scale; patients rate quality of life 'today' and 'the week before using the IPOS' on a scale of 1-7: 1 (very poor) and 7 (excellent). Informal caregiver baseline and follow-up measures involved the Zarit Caregiver Burden Interview-12 (ZBI-12), ${ }^{26}$ where each of the 12 statements is ranked on a Likert scale (0-5): 0 (never) and 5 (nearly always) with a global score of $0-48$ measuring caregivers' perceptions of care demands. ${ }^{26}$ It has been used with caregivers of patients with $\mathrm{CHF}^{27}$ Quantitative data were entered into SPSS V.22.

Patients completed questionnaires by telephone (mean time $14 \mathrm{~min}$ ) at baseline in a 2 -week period preceding IPOS completion, then 1-2 days, 1-2 weeks and 4-6 weeks after IPOS completion. These 
time intervals were selected to enable identification of the optimum time for follow-up measure collection in a future trial. Where longer intervals have been used, the potential effect was thought to have been missed. ${ }^{28}$ Patients requiring assistance with questionnaire completion was used as a feasibility marker.

\section{Feasibility and acceptability}

A priori criteria for study feasibility and acceptability were as follows.

- Recruitment and retention: consent rate of $\geq 40 \%$ of patients approached about the study ${ }^{29}$; recruitment of $\geq 20$ patients $^{15}$ and retention of $\geq 65 \%$, given the high attrition and mortality rate in this population. ${ }^{6} 16$

- Follow-up data feasibility and acceptability: $\geq 90 \%$ completion of each of the questionnaires and items. 3031

- Intervention feasibility and acceptability: $\geq 90 \%$ IPOS completion by retained patients ${ }^{3031}$ and $100 \%$ intervention protocol adherence.

\section{Data collection and management}

Patients for the qualitative interviews were purposively identified to include a broad range of characteristics relevant to the study in terms of age, gender, NYHA class and heart failure type (HFpEF or $\mathrm{HFmrEF} / \mathrm{HFrEF}$ ). Face-to-face interviews were audiorecorded, transcribed by an independent transcription company, checked for accuracy, anonymised and imported into MAXQDA ${ }^{32}$ software to facilitate analysis.

\section{Data analysis}

Study methodology feasibility was examined using the following quantitative data: recruitment, retention, follow-up measure response rates, missing follow-up measure data and missing IPOS data. Quantitative analysis was descriptive statistics and standardised effect size calculation using Cohen's $\mathrm{d}$ where $\mathrm{d}=0.2$ is a small effect size, $\mathrm{d}=0.5$ is medium and $\mathrm{d}=0.8$ is large. ${ }^{33} \mathrm{We}$ applied an analytical framework developed by Bugge et $a l^{34}$ to systematically categorise and explore issues in feasibility studies based on 14 potential methodological issues identified by Shanyinde et al. ${ }^{35}$ Study design and intervention feasibility and acceptability were explored using patient and nurse qualitative semistructured interviews conducted by PMK with a sample size of 18 patients. The potential mechanism of action of the intervention was also examined. These findings are reported separately. ${ }^{36}$ Qualitative data were analysed using framework analysis. ${ }^{37} \mathrm{~A}$ priori codes were drawn from the interview topic guide (see online supplementary appendix 2) study objectives and feasibility guidelines. ${ }^{38}$ PMK was the primary coder. CES coded interviews; consensus on themes and key findings were reached through discussion.

\section{RESULTS}

Recruitment and baseline data collection ran from September 2014 to February 2015. Final qualitative interviews were completed in June 2015. The Bugge et $\mathrm{al}^{34}$ analytical framework was applied to the study findings (table 1).

\section{Recruitment and retention}

Three hundred and seventy-two patients were screened, 81 patients were approached, 38 were recruited and 25 completed the intervention. The proportion of patients approached who consented (conversion to consent) was above the target set (46.9\%). ${ }^{34}$ Figure 1 shows the modified Consolidated Standards of Reporting Trials flow diagram of recruited patients. ${ }^{39}$ Fifteen caregivers were recruited with 10 caregivers retained. Five caregivers were lost due to patient attrition because if a patient withdrew from the study, their caregiver was also withdrawn.

Table 2 shows patients' characteristics. Participants were predominantly male $(56.5 \%)$, mean age $75.4 \pm 9.0$ years of age, NYHA III (65.2\%), HFrEF (52.2\%) and mean Charlson comorbidity index of $4.0 \pm 1.2 .{ }^{40}$

\section{Intervention adherence/compliance}

All eligible nurses participated in education and training and were actively involved in intervention delivery. Intervention adherence was achieved; all 25 retained patients were given the IPOS. Patient compliance was achieved; all 25 patients completed the IPOS with a small proportion $(29,6.4 \%)$ of total missing items. Nineteen of these 29 missing items were from three patients. The most common missing item was appetite, omitted by four patients. Eight patients $(32 \%)$ required assistance with IPOS completion: three from a relative/friend and five from the nurse. Symptoms mentioned in the open questions included pruritus, insomnia, immobility, leg swelling and cough.

\section{Baseline and follow-up data assessment}

Of 25 patients who completed the IPOS, two withdrew after IPOS completion as they were admitted to hospital and were too unwell to continue. The remaining 23 participated in three subsequent telephone data collection points and completed all the questionnaires: there were no missing data for these patients (100\% data completion rate). Table 3 shows the standardised effect sizes at the three time points post-IPOS completion. As the number of measures is large and the sample size is small, these analyses are useful for descriptive purposes only.

\section{Qualitative findings}

Eighteen patients and all four nurses were interviewed postintervention. Interviews ranged from 21 to $44 \mathrm{~min}$ (mean $32 \mathrm{~min}$ ) in length. Patients found the IPOS accessible and appropriate. The intervention was both feasible and acceptable to the nurses as was the study 
Table 1 Summary of the findings against 14 methodological issues for feasibility research

\begin{tabular}{|c|c|c|}
\hline Methodological issues & Findings & Evidence \\
\hline $\begin{array}{l}\text { 1. Did the feasibility study allow a sample size } \\
\text { calculation for the main trial? }\end{array}$ & No & $\begin{array}{l}\text { No, as the effect size on the chosen primary } \\
\text { outcome was too small. }\end{array}$ \\
\hline $\begin{array}{l}\text { 2. What factors influenced eligibility and what } \\
\text { proportion of those approached were eligible? }\end{array}$ & $\begin{array}{l}\text { A proportion of patients were too unwell or too } \\
\text { distressed to be approached }\end{array}$ & Only eligible patients were approached \\
\hline 3. Was recruitment successful? & $\begin{array}{l}\text { Recruitment was difficult, issues with } \\
\text { comprehensive identification of patients }\end{array}$ & NYHA assignment differed between the two sites \\
\hline 4. Did eligible participants consent? & Good conversion to consent & $\begin{array}{l}\text { Thirty-eight recruited out of } 81 \text { eligible, consent } \\
\text { rate of } 46.9 \%\end{array}$ \\
\hline $\begin{array}{l}\text { 5. Were participants successfully randomised and } \\
\text { did randomisation yield equality in groups? }\end{array}$ & Not investigated in this study & Not investigated in this study \\
\hline 6. Were blinding procedures adequate? & Not investigated in this study & Not investigated in this study \\
\hline 7. Did participants adhere to the intervention? & Good adherence to IPOS completion & $\begin{array}{l}\text { Thirty-eight patients recruited, } 25 \text { completed IPOS, } \\
13 \text { LTFU }\end{array}$ \\
\hline $\begin{array}{l}\text { 8. Was the intervention acceptable to the } \\
\text { participants? }\end{array}$ & $\begin{array}{l}\text { Minimal amount of missing IPOS data }(6.4 \%) \text {; } \\
\text { acceptability explored in qualitative interviews }\end{array}$ & $\begin{array}{l}\text { Patients and nurses found the intervention } \\
\text { acceptable and feasible }\end{array}$ \\
\hline $\begin{array}{l}\text { 9. Was it possible to calculate intervention costs } \\
\text { and duration? }\end{array}$ & Cost of the intervention was not assessed & $\begin{array}{l}\text { Costs for resource utilisation were assessed for } \\
\text { participant service use (not reported here) }\end{array}$ \\
\hline 10. Were outcome assessments completed? & $\begin{array}{l}\text { Where participants persisted, there was no } \\
\text { missing data as outcome data were collected on } \\
\text { the telephone }\end{array}$ & $\begin{array}{l}\text { There was no missing data for baseline and } \\
\text { outcome measures }\end{array}$ \\
\hline $\begin{array}{l}\text { 11. Were outcomes measured those that were the } \\
\text { most appropriate outcomes? }\end{array}$ & $\begin{array}{l}\text { Outcomes consistent with the theory underpinning } \\
\text { the intervention were used }{ }^{11}\end{array}$ & See summary of outcome data in table 3 \\
\hline 12. Was retention to the study good? & Once recruited, retention was good & $\begin{array}{l}\text { Response rates: } \\
\text { Time point one questionnaire }(24 / 25) \\
\text { Time point two questionnaire }(23 / 25) \\
\text { Time point three questionnaire }(23 / 25)\end{array}$ \\
\hline $\begin{array}{l}\text { 13. Were the logistics of running a multicentre trial } \\
\text { assessed? }\end{array}$ & $\begin{array}{l}\text { Recruitment was slow at one site until challenges } \\
\text { were identified and addressed. The presence of the } \\
\text { researcher at each site positively influenced the } \\
\text { logistical running of study }\end{array}$ & $\begin{array}{l}\text { Site 1: } 14 \text { patients, eight caregivers } \\
\text { Site } 2 \text { : nine patients, two caregivers }\end{array}$ \\
\hline $\begin{array}{l}\text { 14. Did all components of the protocol work } \\
\text { together? }\end{array}$ & Components worked well together & $\begin{array}{l}\text { There were no difficulties identified in the } \\
\text { various processes and the researcher's ability to } \\
\text { implement them. Patients once recruited were } \\
\text { readily identified. }\end{array}$ \\
\hline
\end{tabular}

Methodological issues based on Shaniyinde et $a^{35}$ and Bugge et al. ${ }^{34}$

IPOS, Integrated Palliative care Outcome Scale; LFTU, lost to follow-up; NYHA, New York Heart Association.

design. The full qualitative findings are presented in the online supplementary appendix 3 .

\section{DISCUSSION}

This study demonstrates that a palliative-specific PROM-based intervention (based on IPOS) with patients with $\mathrm{CHF}$ in nurse-led CHF disease management clinics is feasible and acceptable to patients and staff for research use. The methods used were successful as demonstrated by high compliance and protocol adherence, good patient and caregiver retention and little missing data, demonstrating intervention feasibility and acceptability. The intervention integrated well into the busy nurse-led clinics, complementing existing practice without requiring additional resources. Study implementation strategies were effective, including: reminders to ensure recruited patients received the IPOS, researcher's presence at each study site at IPOS introduction to address any problems and staff engagement. This study's findings will inform a future pilot cluster RCT as they illustrate the effective facilitators and barriers to IPOS use in this population in nurse-led clinics. Service-level randomisation feasibility needs further testing.

Recruitment challenges were expected in this $\mathrm{CHF}$ population ${ }^{41}$ but were compounded by intersite NYHA classification differences necessitating a longer recruitment period. Recruitment initially was difficult at one site with small numbers of eligible patients approached and a high refusal rate which was due to study site differences in NYHA class assignment. NYHA reliability problems are well recognised. ${ }^{42}$ To address this difference, the study site recruiting lower numbers included patients currently assigned NYHA class II who had recently been NYHA class III/IV. This is discussed in depth elsewhere. ${ }^{43}$ IPOS use in a clinical healthcare environment may result in a higher participation rate than in the research setting; the latter can preclude patients from participating. Retention was good from the selected population; 25 of 38 recruited patients $(65 \%)^{16}$ received the intervention and 23 of these $(92 \%)$ completed all follow-up data collection 


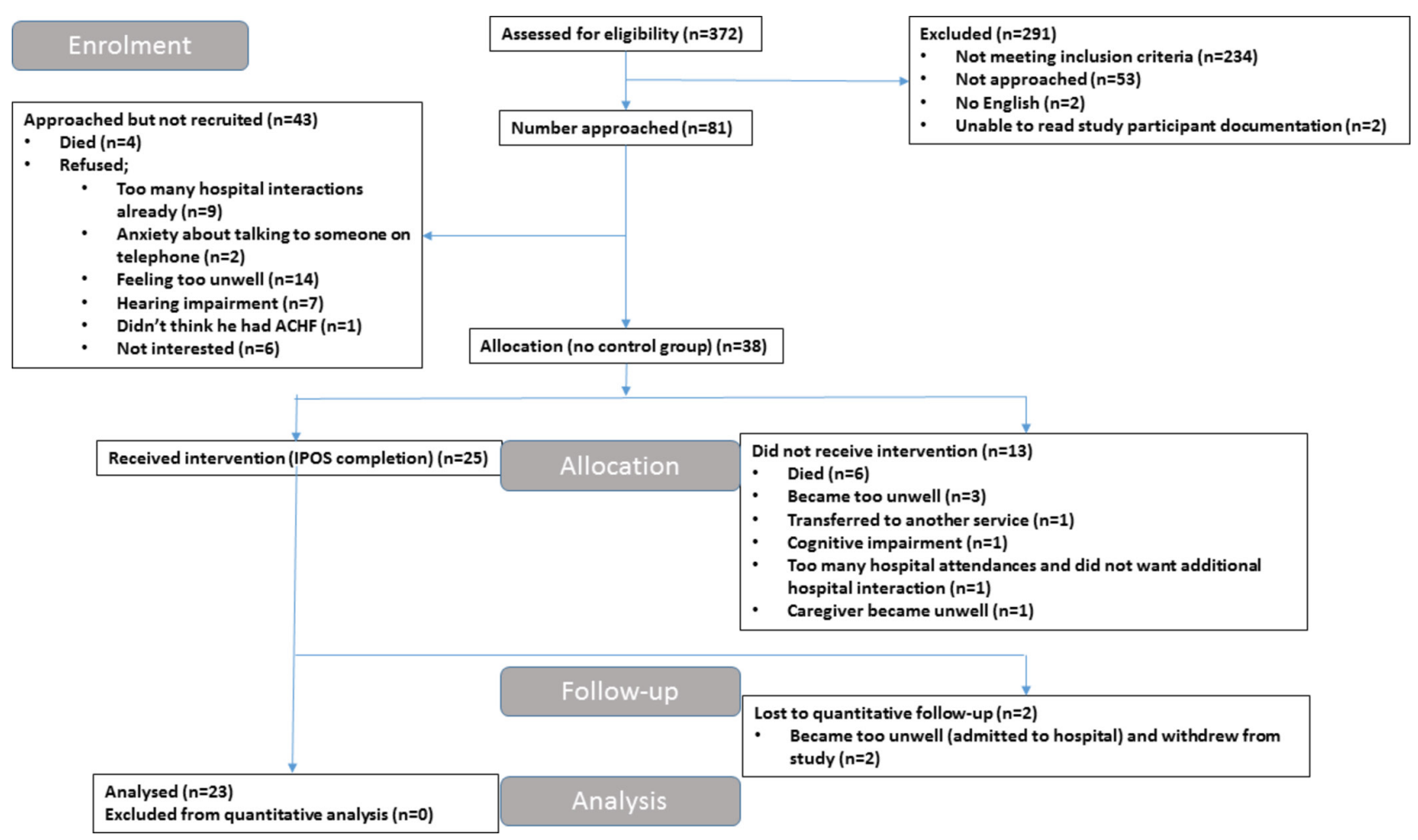

Figure 1 Modified Consolidated Standards of Reporting Trials flow diagram. IPOS, Integrated Palliative care Outcome Scale.

points, suggesting that this study design was feasible in this population. Patient attrition is a recognised challenge in advanced disease studies and may even affirm inclusion of the correct population. ${ }^{44}$

One of the main themes in the qualitative data was IPOS accessibility. Patients described the IPOS as user friendly and having easy readability, including two patients with self-acknowledged suboptimal literacy. Poor literacy is a recognised barrier to PROM accessibility in chronic obstructive pulmonary disease, ${ }^{45}$ which is likely to have resonance with the CHF population. Health numeracy deteriorates with increasing age and cognitive impairment, so being accessible in this way is an important attribute for the IPOS. Cognitive impairment, which was not formally assessed here, may present in up to $75 \%$ of older patients with CHF and is independently associated with $\mathrm{CHF}^{46}$ The IPOS did not lengthen clinical reviews but some patients required more time for IPOS completion. Conducting PROM research in an older population with comorbidities including visual impairment and arthritis can make form filling more challenging; these patients required assistance with IPOS completion. None of the patients found the IPOS burdensome. The IPOS is a generic rather than disease-specific PROM and was designed to assess for palliative symptoms and other concerns. ${ }^{10}$ Those with advanced progressive disease including $\mathrm{CHF}$ and cancer experience many common symptoms, ${ }^{47}$ so it is unsurprising that patients and nurses described the IPOS as appropriate and relevant to their experience of the illness burden in CHF.
Patients with $\mathrm{CHF}$ adjust their lifestyle to reduce symptom exacerbation, therefore reporting less symptom severity. ${ }^{48}$ Time pressures on clinical interactions compound this deficit and the reluctance of patients to vocalise their distress. ${ }^{49}$ Systematic symptom assessment such as the IPOS, identifies significantly more symptoms than patients volunteer. ${ }^{50}$ Participants found this intervention to be an accessible and quick way to assess for palliative symptoms and other concerns. Patients' perceived quality of life relates to how much a disease and its treatment prevent them from achieving their goals. ${ }^{51}$ Arguably, in the setting of chronic progressive disease, where interventions offered are non-curative and not life prolonging, the overall aim should be quality of life improvement. ${ }^{51}$

The ESAS, KCCQ and PHQ- 8 were observed as being feasible with no missing data for retained patients. Telephone quantitative interviews were arranged to suit patients' schedules; this data collection method may partly address the missing data challenges in advanced disease studies. ${ }^{44}$ PHQ-8 telephone administration has been validated. ${ }^{52}$ ESAS and KCCQ telephone administration have been conducted elsewhere. ${ }^{53}$ The small participant number precludes definite conclusions regarding the most appropriate primary outcome measure. While it is not advisable to look for an effect in a feasibility study as it is inadequately powered, ${ }^{54}$ our findings nevertheless provide some information to inform the selection of primary outcome measures and timing for a future definitive trial. It was hypothesised that this intervention would enable patients to identify 


\section{Table 2 Demographics and clinical characteristics}

\begin{tabular}{|c|c|}
\hline & $\begin{array}{l}\text { All } \\
\text { participants } \\
(n=25)\end{array}$ \\
\hline Male, n (\%) & $14(56)$ \\
\hline Age, years $(m e a n \pm S D)$ & $75.7 \pm 9.2$ \\
\hline Married, n (\%) & $15(60)$ \\
\hline \multicolumn{2}{|l|}{ Education, n (\%) } \\
\hline$<$ Secondary School & $12(48)$ \\
\hline Some/completed Secondary School & $9(36)$ \\
\hline Some/completed university & $4(16)$ \\
\hline Body mass index, $\mathrm{kg} / \mathrm{m}^{2}(\operatorname{mean} \pm \mathrm{SD})$ & $27.1 \pm 4.8$ \\
\hline \multicolumn{2}{|l|}{ NYHA functional class, n (\%) } \\
\hline$\|$ & $8(32)$ \\
\hline III & $16(64)$ \\
\hline IV & $1(4)$ \\
\hline Ejection fraction, \% (mean \pm SD) & $39.2 \pm 14.8$ \\
\hline \multicolumn{2}{|l|}{ Type of ejection fraction, n (\%) } \\
\hline HFrEF & $10(40)$ \\
\hline HFmrEF and HRpEF & $15(60)$ \\
\hline Systolic blood pressure $(\mathrm{mm} \mathrm{Hg})($ mean \pm SD) & $118.6 \pm 19.1$ \\
\hline Diastolic blood pressure $(\mathrm{mm} \mathrm{Hg})($ mean \pm SD) & $66.5 \pm 9.7$ \\
\hline Creatinine $(\mu \mathrm{mol} / \mathrm{L})(\mathrm{mean} \pm \mathrm{SD})$ & $129.7 \pm 46.8$ \\
\hline eGFR (mean \pm SD) & $59.9 \pm 29.3$ \\
\hline Diabetes mellitus, type $2, \mathrm{n}(\%)$ & $8(32)$ \\
\hline Chronic obstructive pulmonary disease, $\mathrm{n}(\%)$ & $8(32)$ \\
\hline Hypertension, n (\%) & $14(56)$ \\
\hline Ischaemic heart disease, n (\%) & $17(68)$ \\
\hline Myocardial infarction & $12(48)$ \\
\hline CABG & $12(48)$ \\
\hline $\mathrm{PCl}$ & $9(36)$ \\
\hline Major depression, n (\%) & $5(20)$ \\
\hline Charlson comorbidity index (mean \pm SD) & $4.0 \pm 1.2$ \\
\hline Smoking (including previous smoker), n (\%) & $18(72)$ \\
\hline \multicolumn{2}{|l|}{ Medication use, n (\%) } \\
\hline ACE-i/angiotensin receptor blockers & $20(80)$ \\
\hline Beta-blockers & $25(100)$ \\
\hline Digoxin/amiodarone/ivabradine & $13(52)$ \\
\hline Antidepressants and/or anxiolytics & $7(38)$ \\
\hline Pain medications & $10(40)$ \\
\hline CRT-D (ICD), n (\%) & $12(48)$ \\
\hline
\end{tabular}

ACE-i, ACE inhibitor; CABG, coronary artery bypass grafting; CRT-D, cardiac resynchronisation therapy defibrillator; eGFR, estimated glomerular filtration rate; HFrEF, heart failure reduced ejection fraction; $\mathrm{HFpEF}$, heart failure preserved ejection fraction; HRmrEF, heart failure mid-range ejection fraction; ICD, implantable cardiac defibrillator; $\mathrm{PCI}$, percutaneous coronary intervention.

their symptoms and concerns in order that the nurses act on these, potentially resulting in improved quality of life. Symptom burden (ESAS-r) identified only a small positive effect immediately postintervention which was not sustained. This intervention may have more short-term effects which could be investigated in a larger definitive study. Since this was a feasibility study that was not adequately powered to detect the effect of the intervention, we nevertheless, conducted qualitative interviews to explore the potential mechanism of action of the intervention. This is reported separately. ${ }^{36}$ Patients with CHF need a holistic patient-centred approach ${ }^{28}$ to better understand, identify and address their symptoms and concerns. ${ }^{48}$ The challenges experienced by heart failure professionals in providing holistic care are recognised. ${ }^{55}$ The education and training aimed to support the nurses in how to interpret and act on IPOS feedback and on patient empowerment but did not provide management guidelines. The nurses' actions in response to IPOS feedback were left to their clinical discretion. There is no clear evidence as to which approach is preferable. ${ }^{56}$ One option in a future study may be to identify available services, for example, a physiotherapy-led programme on breathlessness management and incorporate predetermined IPOS criteria into the education and training to prompt referrals. It is here that the value of a mixed methods approach is highlighted. This approach that follows the MRC guidance ${ }^{11}$ and provides greater insight into the feasibility, acceptability and implementation of this complex intervention and pre-post design. $^{57}$

\section{Limitations}

This study only tests the methodology of a pre-post design in urban teaching hospital sites. Therefore, study numbers were too small to detect differences between the two study site populations. Patients recruited to this study accessed nurse-led disease management clinics designed to improve patient clinical outcomes. Therefore, they do not represent the wider CHF population. A pilot cluster RCT would be required to provide a better estimate of the intraclass correlation coefficient to estimate the sample size for a definitive trial. The researcher (PMK) was involved in all study stages: study design, implementation and subsequent evaluation. Since the number of participants was relatively small, true anonymous quantitative evaluation was difficult. This may have introduced bias particularly in assessing acceptability and feasibility of the education and training. However, the nurses correctly interpreted the IPOS and understood the rationale for its use where this was explored in the qualitative interviews; these data findings could potentially be used as a measure of the effectiveness of the education and training. The researcher's role in facilitating study implementation must not be overlooked. The implementation literature ${ }^{58}$ outlines how to investigate researchers' roles in study implementation. However, this was not investigated here. While the IPOS was not modified for heart failure, the open questions allowed patients to highlight additional concerns.

\section{CONCLUSION}

This study identifies that this palliative-specific PROM intervention using the IPOS is feasible and acceptable for patients with $\mathrm{CHF}$ and as it is not burdensome 


\begin{tabular}{|c|c|c|c|c|}
\hline \multirow[b]{2}{*}{ Measure } & \multirow[b]{2}{*}{$\begin{array}{l}\text { Baseline (time point } 0 \text { ) } \\
\text { mean score (SD) } n=25\end{array}$} & \multicolumn{3}{|c|}{ Mean standardised effect size (d) from baseline } \\
\hline & & $\begin{array}{l}\text { Time point } 1 \\
1-2 \text { days post-IPOS (mean } \\
(\bar{x}, \text { SD)) } \mathbf{n}=24\end{array}$ & $\begin{array}{l}\text { Time point } 2 \\
1-2 \text { weeks post- } \\
\text { IPOS (mean, SD) } n=23\end{array}$ & $\begin{array}{l}\text { Time point } 3 \\
4-6 \text { weeks post- } \\
\text { IPOS (mean, SD) } n=23\end{array}$ \\
\hline ESAS-r & $24.72(16.73)$ & $\begin{array}{l}0.05 \\
(\bar{x} 23.9, \text { SD 15.8) }\end{array}$ & $\begin{array}{l}-0.31 \\
(\bar{x} 29.9, \text { SD 19.6) }\end{array}$ & $\begin{array}{l}-0.11 \\
(\bar{x} 26.5, \text { SD 15.0) }\end{array}$ \\
\hline $\begin{array}{l}\text { KCCQ overall clinical } \\
\text { summary score }\end{array}$ & $61.4(25.4)$ & $\begin{array}{l}0.18 \\
(\bar{x} 62.6, \text { SD 25.4) }\end{array}$ & $\begin{array}{l}-0.23 \\
(\bar{x} 56.7, \text { SD 17.2) }\end{array}$ & $\begin{array}{l}-0.02 \\
(\bar{x} 59.8, \text { SD 15.2) }\end{array}$ \\
\hline KCCQ overall summary score & $56.6(16.7)$ & $\begin{array}{l}-0.06 \\
(\bar{x} 56.3, \text { SD 14.7) }\end{array}$ & $\begin{array}{l}-0.09 \\
(\bar{x} 54.4, \text { SD 15.3) }\end{array}$ & $\begin{array}{l}-0.02 \\
(\bar{x} 55.6, \text { SD 16.7) }\end{array}$ \\
\hline KCCQ self-efficacy score & $82.1(18.0)$ & $\begin{array}{l}0.29 \\
(\bar{x} 88.0, \text { SD 11.6) }\end{array}$ & $\begin{array}{l}0.44 \\
(\bar{x} 89.7, \text { SD 9.7) }\end{array}$ & $\begin{array}{l}0.44 \\
(\bar{x} 89.7, \text { SD13.4) }\end{array}$ \\
\hline PHQ-8 & $3.20(4.21)$ & $\begin{array}{l}0.01 \\
\bar{x} 3.0, \text { SD 3.6) }\end{array}$ & $\begin{array}{l}0.10 \\
(\bar{x} 2.8, \text { SD 4.4) }\end{array}$ & $\begin{array}{l}0.10 \\
(\bar{x} 2.8, \text { SD 3.9) }\end{array}$ \\
\hline Quality of life (VAS) & $5.15(1.25)$ & $\begin{array}{l}0.22 \\
(\bar{x} 5.5, \text { SD 1.4) }\end{array}$ & $\begin{array}{l}0.16 \\
(\bar{x} 5.4, \text { SD 1.4) }\end{array}$ & $\begin{array}{l}0.34 \\
(\bar{x} 5.6, \text { SD 1.0) }\end{array}$ \\
\hline ZBI-12 & $21.90(6.92)$ & - & - & $\begin{array}{l}-0.56 \\
(\bar{x} 25.8, \text { SD 3.2) }\end{array}$ \\
\hline
\end{tabular}

ESAS, Edmonton symptom assessment system; IPOS, Integrated Palliative care Outcome Scale; KCCQ, Kansas City Cardiomyopathy Questionnaire; PHQ-8: Patient-Health Questionnaire; VAS: Visual Analogue Scale; ZBI-12: Zarit Caregiver Burden Interview-12.

to patients. This intervention integrated well into nurse-led CHF disease management clinics, did not require additional resource use and did not impede clinical practice. Using the MRC guidance, our findings add to the evidence base and support further development and evaluation of these types of interventions, which this study demonstrates are feasible for research.

Contributors PMK was involved in the conception and design of this study, planning, data collection and analysis and manuscript development and revision. CIES was involved in data analysis, development of the figures and tables, manuscript development and revision. CT, GOG, $\mathrm{CR}$ and $\mathrm{CH}$ were involved in the data collection, development of the figures and tables, manuscript development and revision. BAD and FEM were involved in the conception and design of this study, planning, data analysis, development of the figures and tables, manuscript development and revision. KR, NM, BMA, RM, $\mathrm{IJH}$ and $\mathrm{JK}$ were involved in the planning, development of the figures and tables, manuscript development and revision.

Funding This work was supported by the National Institute for Health Research (NIHR) under the Programme Grants for Applied Research programme grant number (RPPG-1210-12015 C-CHANGE) and the NIHR Collaboration for Leadership in Applied Health Research \& Care (CLAHRC) through CLAHRC South London. This paper presents independent research funded by BuildCARE and part-funded BuildCARE is supported by Cicely Saunders International (CSI) and Atlantic Philanthropies, and led by King's College London, CSI, UK.

Competing interests None declared.

Patient consent Detail has been removed from this case description/these case descriptions to ensure anonymity. The editors and reviewers have seen the detailed information available and are satisfied that the information backs up the case the authors are making.

Ethics approval Research Ethics Committees at each of King's College London, Beaumont Hospital and Mater Misericordiae University Hospital.
Provenance and peer review Not commissioned; externally peer reviewed.

Open Access This is an Open Access article distributed in accordance with the terms of the Creative Commons Attribution (CC BY 4.0) license, which permits others to distribute, remix, adapt and build upon this work, for commercial use, provided the original work is properly cited. See: http://creativecommons.org/licenses/by/4.0/

(C) Article author(s) (or their employer(s) unless otherwise stated in the text of the article) 2017. All rights reserved. No commercial use is permitted unless otherwise expressly granted.

\section{REFERENCES}

1 McMurray JJ, Adamopoulos S, Anker SD, et al. ESC Guidelines for the diagnosis and treatment of acute and chronic heart failure 2012: The Task Force for the Diagnosis and Treatment of Acute and Chronic Heart Failure 2012 of the European Society of Cardiology. Developed in collaboration with the Heart Failure Association (HFA) of the ESC. Eur Heart J 2012;33:1787-847.

2 Epping-Jordan JE, Pruitt SD, Bengoa R, et al. Improving the quality of health care for chronic conditions. Qual Saf Health Care 2004;13:299-305.

3 Allen LA, Stevenson LW, Grady KL, et al. Decision making in advanced heart failure: a scientific statement from the American Heart Association. Circulation 2012;125:1928-52.

4 Jaarsma T, Beattie JM, Ryder M, et al. Palliative care in heart failure: a position statement from the palliative care workshop of the Heart Failure Association of the European Society of Cardiology. Eur J Heart Fail 2009;11:433-43.

5 World Health Organization. Innovative care for chronic conditions: building blocks for action. 2002. http://www.who. int/chp/knowledge/publications/icccreport/en/ (accessed 24 Jun 2015).

6 Kane PM, Murtagh FE, Ryan K, et al. The gap between policy and practice: a systematic review of patient-centred care interventions in chronic heart failure. Heart Fail Rev 2015;20:673-87. 
7 Craig P, Dieppe P, Macintyre S, et al. Developing and evaluating complex interventions: the new Medical Research Council guidance. BMJ 2008;337:a1655.

8 Greenhalgh J, Long AF, Flynn R. The use of patient reported outcome measures in routine clinical practice: lack of impact or lack of theory? Soc Sci Med 2005;60:833-43.

9 Dawson J, Doll H, Fitzpatrick R, et al. The routine use of patient reported outcome measures in healthcare settings. BMJ 2010;340:c186.

10 Schildmann EK, Groeneveld EI, Denzel J, et al. Discovering the hidden benefits of cognitive interviewing in two languages: The first phase of a validation study of the Integrated Palliative care Outcome Scale. Palliat Med 2016;30:599-610.

11 Craig P, Dieppe P, Macintyre S, et al. Developing and evaluating complex interventions: new guidance 2008. ww w.mrc.ac.uk/complexinterventionsguidance (accessed $30 \mathrm{Apr}$ 2013).

12 Creswell JW, Clark P, Vicki L. Designing and conducting mixed methods research. 2nd edn. Los Angeles: Sage Publications, 2011.

13 Metra M, Ponikowski P, Dickstein K, et al. Advanced chronic heart failure: a position statement from the Study Group on Advanced Heart Failure of the Heart Failure Association of the European Society of Cardiology. Eur J Heart Fail 2007;9:684-94.

14 Ponikowski P, Voors AA, Anker SD, et al. 2016 ESC Guidelines for the diagnosis and treatment of acute and chronic heart failure: the Task Force for the diagnosis and treatment of acute and chronic heart failure of the European Society of Cardiology (ESC) developed with the special contribution of the Heart Failure Association (HFA) of the ESC. Eur Heart J 2016:37:2129-200.

15 Faulkner L. Beyond the five-user assumption: benefits of increased sample sizes in usability testing. Behav Res Methods Instrum Comput 2003;35:379-83.

16 Stow R, Ives N, Smith C, et al. A cluster randomised feasibility trial evaluating nutritional interventions in the treatment of malnutrition in care home adult residents. Trials 2015;16:433.

17 Hoffmann TC, Glasziou PP, Boutron I, et al. Better reporting of interventions: template for intervention description and replication (TIDieR) checklist and guide. BMJ 2014;348:g1687.

18 Knowles M. Androgogy in action: applying modern principles of adult learning. San Francisco: Jossey-Bass, 1984.

19 Bekelman DB, Hutt E, Masoudi FA, et al. Defining the role of palliative care in older adults with heart failure. Int J Cardiol 2008;125:183-90.

20 Malik FA, Gysels M, Higginson IJ. Living with breathlessness: a survey of caregivers of breathless patients with lung cancer or heart failure. Palliat Med 2013;27:647-56.

21 Ezekowitz JA, Thai V, Hodnefield TS, et al. The correlation of standard heart failure assessment and palliative care questionnaires in a multidisciplinary heart failure clinic. J Pain Symptom Manage 2011;42:379-87.

22 Green CP, Porter CB, Bresnahan DR, et al. Development and evaluation of the Kansas City Cardiomyopathy Questionnaire: a new health status measure for heart failure. J Am Coll Cardiol 2000;35:1245-55.

23 Pressler SJ, Subramanian U, Perkins SM, et al. Measuring depressive symptoms in heart failure: validity and reliability of the patient health questionnaire-8. Am J Crit Care 2011;20:146-52.

24 Spertus J, Peterson E, Conard MW, et al. Monitoring clinical changes in patients with heart failure: a comparison of methods. Am Heart J 2005;150:707-15.

25 Kroenke K, Strine TW, Spitzer RL, et al. The PHQ-8 as a measure of current depression in the general population. J Affect Disord 2009;114:163-73.
26 Bédard M, Molloy DW, Squire L, et al. The Zarit Burden Interview: a new short version and screening version. Gerontologist 2001;41:652-7.

27 Malik FA, Gysels M, Higginson IJ. Living with breathlessness: a survey of caregivers of breathless patients with lung cancer or heart failure. Palliat Med 2013;27:647-56.

28 Ekman I, Wolf A, Olsson LE, et al. Effects of person-centred care in patients with chronic heart failure: the PCC-HF study. Eur Heart J 2012;33:1112-9.

29 Bajwah S, Ross JR, Wells AU, et al. Palliative care for patients with advanced fibrotic lung disease: a randomised controlled phase II and feasibility trial of a community case conference intervention. Thorax 2015;70:830-9.

30 Schulz KF, Grimes DA. Sample size slippages in randomised trials: exclusions and the lost and wayward. Lancet 2002;359:781-5.

31 Preston NJ, Fayers P, Walters SJ, et al. Recommendations for managing missing data, attrition and response shift in palliative and end-of-life care research: part of the MORECare research method guidance on statistical issues. Palliat Med 2013;27:899-907.

32 VERBI Software. MAXQDA, software for qualitative data analysis 1986-2016. http://www.maxqda.com/ (accessed 15 May 2015).

33 Cohen J. Statistical power analysis for the behavioral sciences. New York, NY: Academic Press; Taylor and Francis 1969, 2013.

34 Bugge C, Williams B, Hagen S, et al. A process for decisionmaking after pilot and feasibility Trials (ADePT): development following a feasibility study of a complex intervention for pelvic organ prolapse. Trials 2013;14:353.

35 Shanyinde M, Pickering RM, Weatherall M. Questions asked and answered in pilot and feasibility randomized controlled trials. BMC Med Res Methodol 2011;11:117.

36 Kane PM, Ellis-Smith C, Daveson BA, et al. Understanding how a palliative-specific patient reported outcome measure intervention works to facilitate patient-centred care in advanced heart failure: a qualitative study. KCL 2017.

37 Ritchie J, Spencer L. Qualitative data analysis for applied policy research. In: Analysis of qualitative data.

38 Bowen DJ, Kreuter M, Spring B, et al. How we design feasibility studies. Am J Prev Med 2009;36:452-7.

39 Moher D, Hopewell S, Schulz KF, et al. CONSORT 2010 explanation and elaboration: updated guidelines for reporting parallel group randomised trials. Int J Surg 2012;10:28-55.

40 Quan $\mathrm{H}, \mathrm{Li}$ B, Couris CM, et al. Updating and validating the Charlson comorbidity index and score for risk adjustment in hospital discharge abstracts using data from 6 countries. Am J Epidemiol 2011;173:676-82.

41 Fitzsimons D, Strachan PH. Overcoming the challenges of conducting research with people who have advanced heart failure and palliative care needs. Eur J Cardiovasc Nurs 2012;11:248-54.

42 Raphael C, Briscoe C, Davies J, et al. Limitations of the New York Heart Association functional classification system and self-reported walking distances in chronic heart failure. Heart 2007;93:476-82.

43 Kane PM, Murtagh FE, Ryan KR, et al. Strategies to address the shortcomings of commonly used advanced chronic heart failure descriptors to improve recruitment in palliative care research: a parallel mixed-methods feasibility study. Palliat Med 2017;27:026921631770642.

44 Higginson IJ, Evans CJ, Grande G, et al. Evaluating complex interventions in end of life care: the MORECare statement on good practice generated by a synthesis of transparent expert consultations and systematic reviews. BMC Med 2013;11:111.

45 Jahagirdar D, Kroll T, Ritchie K, et al. Patient-reported outcome measures for chronic obstructive pulmonary disease: the exclusion of people with low literacy skills and learning disabilities. Patient 2013;6:11-21. 
46 Hajduk AM, Kiefe CI, Person SD, et al. Cognitive change in heart failure: a systematic review. Circ Cardiovasc Qual Outcomes 2013;6:451-60.

47 Solano JP, Gomes B, Higginson IJ. A comparison of symptom prevalence in far advanced cancer, AIDS, heart disease, chronic obstructive pulmonary disease and renal disease. J Pain Symptom Manage 2006;31:58-69.

48 Ekman I, Cleland JG, Andersson B, et al. Exploring symptoms in chronic heart failure. Eur J Heart Fail 2005; 7:699-703.

49 Leeming A, Murray SA, Kendall M. The impact of advanced heart failure on social, psychological and existential aspects and personhood. Eur J Cardiovasc Nurs 2014;13:162-7.

50 Homsi J, Walsh D, Rivera N, et al. Symptom evaluation in palliative medicine: patient report vs systematic assessment. Support Care Cancer 2006;14:444-53.

51 McKenna SP. Measuring patient-reported outcomes: moving beyond misplaced common sense to hard science. BMC Med 2011;9:86.

52 Wells KB, Burnam MA, Leake B, et al. Agreement between face-to-face and telephone-administered versions of the depression section of the NIMH diagnostic interview schedule. J Psychiatr Res 1988;22:207-20.

53 Evangelista LS, Lombardo D, Malik S, et al. Examining the effects of an outpatient palliative care consultation on symptom burden, depression, and quality of life in patients with symptomatic heart failure. J Card Fail 2012;18:894-9.

54 Arain M, Campbell MJ, Cooper CL, et al. What is a pilot or feasibility study? A review of current practice and editorial policy. BMC Med Res Methodol 2010;10:67.

55 Cowie MR. Person-centred care: more than just improving patient satisfaction? Eur Heart J 2012;33:1037-9.

56 Greenhalgh J, Dalkin S, Gooding K, et al. CHealth services and delivery research: BFunctionality and feedback: a realist synthesis of the collation interpretation and utilisation of patient-reported outcome measures data to improve patient care. 2017.

57 Curry LA, Krumholz HM, O'Cathain A, et al. Mixed methods in biomedical and health services research. Circ Cardiovasc Qual Outcomes 2013;6:119-23.

58 Peters DH, Tran NT, Adam T. Implementation research in health: a practical guide. 2013 (accessed 18 Dec 2015). 